\title{
IMPLEMENTASI TRI KAYA PARISUDHA DALAM PENDIDIKAN KARAKTER SISWA SD NEGERI 8 BAN KECAMATAN KUBU, KABUPATEN KARANGASEM
}

\author{
I Nengah Sumada \\ Pascasarjana Pendidikan Agama Hindu \\ Universitas Hindu Indonesia \\ Denpasar
}

\begin{abstract}
ABSTRAK
Pendidikan merupakan usaha sadar yang dilakukan secara terus menerus dan berkelanjutan. Pendidikan karakter menjadi bagian yang sangat utama dalam upaya mewujudkan tujuan pendidikan nasional. Untuk membangun dan menumbuhkan karakter masyarakat dilakukan pengalian dan pengkajian nilai-nilai agama Hindu. Salah satunya dengan mengimplementasikan Tri Kaya Parisudha dalam pendidikan karakter. Dengan mengimplementasikan Tri Kaya Parisudha dalam pendidikan karakter siswa SD Negeri 8 Ban dapat dijadikan sebagai landasan/pondasi membangun karakter, memberi arahan untuk pembangunan karakter, Tri Kaya Parisudha merupakan cerminan karakter. Dalam pengimplementasian Tri Kaya Parisudha dapat dilakukan melalui tiga cara yaitu : membiasakan berpikir yang baik, membiasakan berkata dengan baik, membiasakan bertindak yang baik.
\end{abstract}

Kata Kunci: Implementasi, Tri Kaya Parisudha, Pendidikan Karakter 


\begin{abstract}
Education is a counsious effort done steadily and sustainable. Education character be part of a very main in an effort to relize the purpose of ntional education. To build and it foster a character assessment conducted excavations and community values religion Hindu. One of them with to implementation tri kaya parisudha in education character. With to implementation tri kaya parisudha the education character students elementary School of 8 Ban can be used as based build character, give directives to character development, tri kaya parisudha is a reflection of the character. In the to implementation tri kaaya parisudha can be done through three ways that familiarize think is good, familiarize said that good and familiarize act good.
\end{abstract}

Key Word: Implementation, Tri Kaya Parisudha, Education Charakcer

\title{
I. PENDAHULUAN
}

Pada dasarnya pendidikan adalah pengembangan manusia ke taraf insani. Sedangkan Ki Hajar Dewantara menyatakan bahwa pendidikan merupakan tuntutun pertubuhan anak-anak. Menurut Ibrahim Akbar (2009:38) praktik pendidikan di Indonesia justru lebih berorientasi pada pendidikan berbasis kerampilan teknis yang bersifat mengembangkan intelektual saja, kurang mengindahkan kemampuan emosional dan spiritual. Bahkan tak jarang guru memiliki pretensi bahwa peserta didik yang memiliki kompetensi yang baik hanya bisa dilihat melalui hasil ujiannya saja, tidak melalui penanaman sikap, karakter, dan mengimplementasi nilai-nilai kebudayaan. Ini benarbenar ironis dan terjadi dalam dunia pendidikan.

Sekolah merupakan salah satu pendidikan formal yang memiliki mandat yang kucup berat dalam mewujudkan pendidikan nasional. Sekolah selalu dituntut untuk bisa mentranformasi nilai pendidikan budaya dan karakter terhadap para siswa. Namun pendidikan karakter di sekolah tidak bisa terbentuk secara instan, tetapi harus dilatih secara lebih serius dan proporsional agar mencai bentuk dan kekuatan yang idial. Salah satu sekolah dasar (SD) yang berada dipedalaman yaitu di desa Ban. Sekolah yang berada dikaki gunung agung ini merupakan sekolah yang seluruhnya siswanya berasal warga pedalaman yakni warga Banjar Dinas Bonyoh. Seluruh warga disana adalah petani 
sehingga pemahaman akan pendidikan masih sangat kurang. Tingkah laku siswa cenderung mencotoh dari yang mereka temui baik di televisi, maupun media online dan media sosial.

Berdasarkan keinginan tersebutlah maka pada SD Negeri 8 Ban Kecamatan Kubu Kabupaten Karangasem dilakukan penelitian tentang Implementasi Tri Kaya Parisudha dalam Mengembangkan Karakter Siswa. Tri Kaya Parisudha artinya tiga prilaku yang dimuliakan dan disucikan oleh umat hindu. Bagiannya adalah Manacika Parisudha, Wacika Parisudha, dan Kayika Parisudha Subagiasta (2007:14).

Atmaja (2010:45) mengungkapkan tentang Tri Kaya Parisudha dan bagian-bagiannya yaitu (1) Manacika adalah pikira secara umum sebagai umat hindu dituntut untuk berikir yang baik dan benar, (2) Wacika adalah perkartaan, secara umum sebagai umat Hindu dituntut untuk berkata atau berbicara yang baik dan benar, (3) Kayika adalah perbuatan, secara umum sebagai umat Hindu dituntut untuk bisa berbuat atau melakukan aktipitas yang baik dan benar.

Penelitian ini penting lakukan, mengingat kegalauan dunia pendidikan tentang munculnya banyak kejadian memprihatinkan terkait prilaku peserta didik yang tuna rungu, cara berbicara siswa yang kurang sopan, kehadiran peserta didik yang tidak tepat waktu, dalam persembahyang peserta didik sering bermain-main. Dalam peneltian ini mempergunakan dua teori yaitu teori behaviorisme dan teori konstruktivisme. Data yang diperoleh lebih banyak melalui pengamatan (observasi) dan wawancara baik yang terstruktur maupun tidak terstruktur.

\section{PEMBAHASAN}

\subsection{Tri Kaya Parisudha Diimplementasikan Dalam Pendidikan Karakter Siswa SD Negeri 8 Ban Kecamatan Kubu, Kabupaten Karangasem}

Ajaran Tri Kaya Parisudha termasuk dalam etika Hindu yang berarrti tiga perbuatan yang harus disucikan yaitu manacika, wacika dan kayika. Setiap hal yang dilakukan oleh manusia, itu diawali oleh pikiran, kemudian perkataan dan diwujudkan melalui perbuatan.

Menurut I Nengah Suciarta yang merupakan guru agama Hindu di SD Negeri 8 Ban mengungkapkan bahwa menumbuhkan karakter anak dimulai dari membiasakan hal-hal yang kecil seperti berbicara menggunakan bahasa Bali kasar, mengambil dan memberikan sesuatu 
dari atau kepada orang lain mempergunakan tangan kiri, (wawancara, 23 Juli 2018). Lebih lanjut kepala SD Negeri 8 Ban juga menerangkan bahwa karakter anak akan terbentuk sesuai dengan kebiasaankebiasaan yang ditanamkan dari lingkungan keluarga, dan lingkungan masyarakat dari daerah mereka tinggal. Hal-hal itu sangat mempengaruhi kepribadian anak-anak tersebut.

Membentuk dan mengembangkan karakter merupakan suatu sikap yang harus dibiasakan dan diteladankan. Keteladanan harus dilakukan oleh guru. Dalam konsep agama Hindu yang mengenal catur guru yakni guru rupaka (orang tua di rumah), guru pengajian (orang tua disekolah), guru wisesa (pemerintah) dan guru swadyaya (Tuhan/Ida Sang Hyang Widhi Wasa). Jadi dengan mengacu pada ajaran catur guru tersebut, semua elemen masyarakat mesti terlibat demi tumbuh kembangnya karakter siswa.

Hal ini sesuai dengan yang diungkapkan dalam gagasan Tim Penyusun Pengembangan Karakter di Perguruan Tinggi bahwa pendidikan karakter bangsa membutuhkan pendekatan dan salah satu pendekatannya yakni pendekatan kateladanan. Penanaman nilai-nilai karakter ke-Indonesianan atau kepribadian Pancasila tidak hanya lewat omongan atau ajakan, tetapi yang lebih penting adalah melalui pemodelan atau contoh-contoh nyata. Misalnya, pemodelan dilakukan oleh guru, kepala sekolah dll. Pemodelan bisa lebih berhasil, tidak saja karena empirik, tetapi juga karena budaya Indonesia yang bersifat paternalistik atau bapakisme, (Atmadja, dkk.,2017:13).

Membangun karakter yang dilandasi Tri Kaya Parisudha dilakukan melalui suatu pembiasaan dari cara berpikir, berkata dan berprilaku. Dalam berkata yang baik tidak hanya berkomunikasi dengan bahasa yang sopan tetapi mampu untuk menghargai setiap pendapat teman-teman di kelas tanpa mengutamakan pendapat tersebut benar. Tetapi lebih menghargai sikap siswa yang mau menyampaikan pendapatnya. Hal tersebut merupakan salah satu cara untuk menumbuhkan sikap yang berani menyampaikan pendapatnya didepan umum.

Selain itu juga menurut I Nengah Suata bahwa para guru harus menjadi contoh dan teladan dalam berbicara sehingga para guru harus mengikuti cara berkomunikasi siswa. Para guru juga harus mencontohkan cara menanggapi dan menghargai pendapat orang lain, sehingga siswa tidak merasa malu dan bahkan harus termotivasi untuk mengeluarkan pendapat-pendapat berikutnya. 


\subsection{Tata Cara Implementasi Tri Kaya Parisudha Dalam Pendidikan Karakter Di SD Negeri 8 Ban Kecamatan Kubu}

Didalam memulai setiap perbuatan, semestinya diawali dengan berpikir atau manacika. Manacika Parisudha dengan demikian dapat diartikan sebagai berpikir yang benar, baik dan suci. Pikiran adalah inti dari segalanya. Dari ketiga unsur Tri Kaya Parisudha, pikiran adalah paling pokok, yang dapat menimbulkan adanya perkataan maupun perbuatan. Pikiran yang baik, benar, bersih dan suci, tentu akan menimbulkan perkataan dan perbuatan yang baik pula. Sebaliknya pikiran yang tidak baik, akan dapat menimbulkan perkataan dan perbuatan yang buruk. Karena itu pikiran adalah paling penting untuk dikendalikan.

Pendapat yang sama juga diungkapkan oleh kepala SD Negeri 8 Ban yakni Bapak I Gede Tianyar Riawan yang mengungkapkan bahwa:

Semua siswa SD Negeri 8 Ban, sebelum memulai kegiatan belajar dan mengajar diajak sembahyang bersama di Padmasana dengan dipimpin oleh guru agama, setelah itu siswa diberikan pengarahan dengan tujuan untuk mempersiapkan pikiran siswa dan mental siswa sebelum belajar. Selain itu juga biar mereka memahami penting belajar, (wawancara, Senin, 23 Juli 2018)

Jadi para siswa sebelum memulai suatu kegiatan pembelajaran terlebih dahulu mereka diarahkan dan disiapkan pikiran dan mentalnya, agar tujuan belajar yang mereka harapakan dari rumahnya ke sekolah bisa dicapai. Apabila itu tidak dilakukan maka terkadang para siswa malas untuk mengikuti pelajaran. Mereka lebih senang bermain-main saja dan mereka hanya menghabiskan uang saku ke sekolah. Hal itu juga dibenarkan oleh salah seorang wali murid yang menyatakan bahwa:

"Siswa yang datang ke sekolah lebih banyak duduk dan bermain bersama teman-temannya, mereka mengabaikan tugas-tugas piket. Mereka duduk, bermain, dan berbelanja. Jika mereka tidak ingatkan atau ditegur maka mereka akan tetap acuhdengan tugas-tugas piketnya,(wawancara, 23 Juli 2018).

Mengacu pada kutipan bait di atas bahwa berkata-kata yang diucapkan haruslah kata-kata yang membuat kebaikan, kebahagian. Dan tidak boleh melebih-lebihkan setiap kebaikan itu hanya demi sebuah pengakuan sebagai orang yang pandai berbicara. Serta mesti 
disadari bahwa kata-kata akan berakibat panjang karena ada yang senang dengan kata-kata tersebut atau juga ada yang benci dengan kata-kata tersebut.

Dalam mengarahkan siswa SD Negeri 8 Ban dalam menjaga setiap perkataannya agar menyenangkan dan mendatangkan kebaikan, dengan tidak berkata-kata kasar, tidak saling mengejek. Seperti yang diungkapkan oleh guru agama di SD tersebut. Bapak I Nengah Suciarta yang ditemuai pada hari Selasa, 24 Juli 2018 mengungkapkan:

"Setiap hari anak-anak selalu diingatkan dan dinasehati baik oleh kepala sekolah, wali kelas maupun guru mata pelajaran agar dalam berbicara tidak mempergunakan bahasa yang kasar dan jangan mengejek teman. Apabila bercanda pergunakanlah katakata yang pantas".

Setiap perbuatan, apakah perbuatan baik ataukah perbuatan buruk akan dapat menimbulkan apa yang dinamakan karma. Perbuatan yang baik akan menimbulkan karma baik. Sebaliknya perbuatan yang buruk akan menimbulkan karma buruk. Karma itu adalah pahala atau hasil dari perbuatan kita. Semua manusia tentu tidak ingin memetik karma buruk. Karena itu janganlah berbuat yang tidak baik yang dapat menciptakan karma buruk.

Selain itu juga anak-anak diajarkan untuk peduli dengan sesamanya, yakni pada saat ada salah satu siswa yang tidak hadir ke sekolah dalam 1 (satu) karena sakit, maka seluruh warga sekolah memberikan sumbangan seikhlasnya. Hal itu diungkapkan oleh kepala SD Negeri 8 Ban yang mengungkapkan untuk membiasakan kepedulian dan menumbuhkan rasa kemanusiaan, maka setiap siswa yang sakit dan tidak hadir ke sekolah dalam waktu seminggu akan diberikan sumbangan dan dikunjungi oleh perwakilan kelas, (wawancara, Senin 23 Juli 2018).

\subsection{Implikasi Implementasi Tri Kaya Parisudha Dalam Pendidikan Karakter Siswa Sd Negeri 8 Ban Kecamatan Kubu Kabupaten Karangasem}

Adapun implikasi dari mengimplementasikan ajaran Tri Kaya Parisudha dalam pendidikan karakter siswa SD N 8 Ban dapat dilihat dari sikap dan prilaku siswa yaitu: manacika parisudha merupakan 
pikiran, yang secara umum ajaran agama Hindu dituntut agar dapat berpikir yang baik dan benar. Dari hasil pengamatan dan wawancara terhadap siswa SD Negeri 8 Ban Dalam hal ini perlunya semua guru berkerjasama saling isi mengisi, bertukar pendapat dan memberi keteladanan dalam berbagai sikap dan perbuatan kepada peserta didik tanpa terkecuali, baik kepada guru kelas, kepala sekolah, staf yang ada di SD Negeri 8 Ban bahkan kepada orang tua wali murid dan komite sekolah.

Mengingat bahwa masalah kepribadian anak merupakan masalah yang sangat pelik dan mendasar, seolah - olah hal ini hanya menjadi tanggung jawab guru agama Hindu dan guru di sekolah saja, sebab pengawasan guru terhadap perilaku anak di sekolah sangat terbatas waktunya, demikian menurut pendapat I Nengah Suciarta. Namun disisi lain orang tua/wali murid sebagaian besar menyerahkan penuh tanggung jawab pendidikan itu kepada guru di sekolah.

Di sisi lain kepala sekolah telah berupaya memberikan penjelasan dan penyadaran kepada orangtua murid bahwa masalah pendidikan merupakan tanggung jawab kita bersama yaitu keluarga, sekolah dan pemerintah. Dorongan motivasi dan cinta kasih yang menjiwai hubungan orang tua dengan anak. Orang tua/wali murid harus senantiasa mengawasi anak dalam hal belajar, serta mengisi waktu dengan kegiatan yang bermanfaat bagi anak, tidak ada lagi anggapan orang tua siswa seolah-olah masalah pendidikan menjadi tanggung jawab guru di sekolah semata.

Dengan penerapan Tri Kaya Parisudha di SD Negeri 8 Ban Kecamatan Kubu terlihat pada sikap anak yakni pada saat mengikuti pembelajaran yang sudah tumbuh motivasi dalam belajar. Siswa-siswa SD Negeri 8 Ban memahami makna belajar secara menyeluruh. Begitu juga siswa menunjukkan sikap yang saling menghormati. Karena telah dipahami akan yang diucapkan dan dilakukan bermula dari yang dipikirkan. Sehingga para siswa begitu memikirkan setiap yang akan diucapkan, dikatakan dan dilakukan. Hal ini terlihat tidak lagi ada pertengkaran atau perkelahian. Dalam kegiatan pembelajaran siswa tidak menjawab asal-asalan atau bahkan ceplas-ceplos. Selain itu, para guru dan TU memberikan suatu keteladanan dalam berbicara. Semua guru ikut membina siswa dengan mempergunakan kata-kata yang sopan dan tidak mempergunakan kata-kata yang kurang baik.

Dalam menumbuhkan kejujuran, I Nengah Suciarta selaku guru SD Negeri 8 Ban membiasakan dengan menerapkan ajaran panca satya yakni satya wacana (taat akan perkataan), satya semaya (taat akan janji), satya mitra (taat akan teman), satya laksana (taat akan 
perbuatan), dan satya hredaya (taat akan kata hati). I Nengah Suciarta dan para guru lainnya begitu banyak menekankan tentang taat akan perkataan. Artinya para siswa dibimbing dan diarahkan untuk mampu menjadi pribadi yang bertanggung jawab akan setiap dampak yang timbul dari perkataan.

Didalam menumbuhkan prilaku yang baik erat kaitannya dengan kedisplinan. Menurut I Nengah Suciarta selaku guru agama Hindu di SD Negeri 8 Ban, mengungkapkan bahwa guru perlu menerapkan sanksi-sanksi yang bersifat mendidik, terutama bagi siswa yang melanggar aturan dalam hal pembelajaran, seperti mengganggu sedang belajar, membuat keributan yang tidak bermanfaat, mengejek teman-temannya.

Melalui pembinaan dan pengarahan, para siswa SD Negeri 8 Ban Kecamatan Kubu Kabupaten Karangasem, para siswa mengalami perubahan sikap yang baik, diantaranya siswa mau dengan sadar mengerjakan kegiatan 7K (Kebersihan, Ketertiban, Kerapian, Kekeluargaan, Kerindangan, Keindahan, Keamanan) tanpa diawasi oleh para guru. Para siswa pun dapat saling bekerjasama dalam menyelesaikan tugas-tugas $7 \mathrm{~K}$ dengan teman sekelasnya. Para siswa dapat menumbuhkan suasana kekeluargaan yang penuh kehangantan dengan saling menghormati.

\section{PENUTUP}

Dari penjelasan hasil penelitian yang telah diuraikan, maka dapat disimpulkan bahwa tri kaya parisudha diimplementasikan dalam pendidikan karakter siswa SD Negeri 8 Ban Kecamatan Kubu Kabupaten Karangasem dijadikan sebagai landasan/pondasi membangun karakter, memberi arahan untuk pembangunan karakter, Tri Kaya Parisudha merupakan cerminan karakter. Implementasi Tri Kaya Parisudha dalam pendidikan karakter siswa SD Negeri 8 Ban Kecamatan Kubu Kabupaten Karangasem dilakukan dengan tiga cara yaitu membiasakan berpikir yang baik, membiasakan berkata dengan baik, membiasakan bertindak yang baik. Implikasi implementasi tri kaya parisudha dalam pendidikan karakter siswa SD Negeri 8 Ban yakni (1) cara berpikir (manacika), (2) cara berkata (wacika), (3) cara berbuat (kayika). 


\section{DAFTAR PUSTAKA}

Atmaja, Nada I Made, dkk. 2010. Etika Hindu. Surabaya: Paramita.

Kementerian Pendidikan Nasional. 2010. Modul Pendidikan Karakter Bangsa. Jakarta: Ditjen Dikdasmen.

Subagiasta, I Ketut. 2007. Etika Pendidikan Agama Hindu. Surabaya: Paramita.

Suwardani, Ni Putu. 2010. Membangun Pendidikan Karakter yang Berbudaya. Denpasar: UNHI.

Titib I Made, 2006. Menumbuhkembangkan Pendidikan Budhi Pekerti Pada Anak. Denpasar: Pustaka Bali Post.

Trianto. 2007. Model-Model Pembelajaran Inovatif Berorientasi Konstruktifistik. Jakarta: Prestasi Pustaka.

Wiana I Ketut, 2009. Cara Belajar Agama Hindu yang Baik. Denpasar: Pustaka BaliPost.

Yudha Triguna, Ida Bagus Gde. 2017. Budaya Inspiratif dan Membangun Karakter. Tabanan: Pustaka Ekspresi. 